\title{
Movements in Real Estate Uncertainty in the United States: The Role of Oil Shocks ${ }^{\#}$
}

\author{
Rangan Gupta*, Xin Sheng ${ }^{* *}$ and Qiang Ji ${ }^{* * *}$
}

\begin{abstract}
In this paper, we analyse the role played by disaggregated oil shocks in driving real estate uncertainty (REU) over the monthly period of 1975:02 to 2017:12, based on impulse response functions generated from the local projection method. We find that the oil-specific consumption demand shock is statistically the strongest predictor of higher future REU, followed by the significant negative impact from the aggregate supply shock, especially for long-run REU. While the oil inventory demand shock has a short-lived positive impact on REU, global economic activity shock virtually plays no role in driving the same. Our results have important implications for policymakers and investors.
\end{abstract}

Keywords: Oil shocks, real estate uncertainty, local projection model, impulse response functions

JEL Codes: C22, Q41, R30

\section{Introduction}

Following the "Great Moderation", the world economy experienced a substantial increase in financial and macroeconomic volatility as a result of the global financial crisis starting in the summer of 2007, followed by a major global recession (the "Great Recession") between 2008 and 2009, and regional crises such as the sovereign debt crisis in Europe starting in 2010. As a result, the analysis of the role of volatility and uncertainty in the macroeconomy has regained a prominent role in recent years (see, Chuliá et al., (2017), and Gupta et al., (2018, 2019, 2020) for detailed reviews of this literature), with the majority of these studies concluding that unexpected large changes in uncertainty (or the closely related concepts of risk and volatility) represent an important source of macroeconomic (and financial markets) fluctuations. In this regard, given that the source of the recent financial turmoil originated in the housing market of the United States (US), Nguyen Thanh et al., (2018) construct a new uncertainty measure that is specific to the real estate sector, and shows that real estate uncertainty (REU) not only negatively impact the housing market (house prices and housing starts), but also overall macroeconomic activity (industrial production).

While in general, uncertainty was considered to be reflecting exogenous factors such as natural disasters or geopolitical turmoil, a growing consensus is that uncertainty actually arises as an endogenous response to other macroeconomic forces, such as specific aggregate demand or aggregate supply shocks, thus contributing to amplifying their effects (Mumtaz and Musso, 2019; Ludvigson et al., forthcoming). Given this, a question of paramount importance for policymakers is to determine the possible factors that can drive uncertainty, since predicting the path of uncertainty, which is a leading indicator (as concluded by the extant literature outlined above), would allow policy authorities to determine in which direction the

\footnotetext{
\# We would like to thank two anonymous referees for many helpful comments. However, any remaining errors are solely ours.

*Department of Economics, University of Pretoria, Pretoria, 0002, South Africa. Email: rangan.gupta@up.ac.za.

** Lord Ashcroft International Business School, Anglia Ruskin University, Chelmsford, CM1 1SQ, United Kingdom. Email: xin.sheng@anglia.ac.uk.

*** Corresponding author. Institutes of Science and Development, Chinese Academy of Sciences, Beijing 100190, China. Email: jqwxnjq@163.com or jqwxnjq@casipm.ac.cn.
} 
macroeconomy and financial markets are headed, and accordingly decide on the appropriate policy response. In this regard, a series of recent studies (see Degiannakis et al., (2018) and Hailemariam et al., (2019) for detailed literature reviews) demonstrate that oil shocks, in particular aggregate demand innovations, are a major driver of macroeconomic uncertainty (with the transmission operating via direct and indirect channels associated with investments, inflation, production, and the size of the public sector).

Note that, the oil market can specifically affect the housing sector via multiple channels, as outlined in Antonakakis et al., (2016). For instance, the recessionary impact of oil price increases is likely to dampen the demand for housing. But while this is true for an oil-importing country, for an oil exporter, like the US in the wake of the "Shale Revolution", increases in oil prices are likely to cause a boom in the economy, and thus increase housing market activity from the demand-side. But at the same time, oil price increases, irrespective of an oil exporter and importer, are likely to increase construction and operational building costs, and cause a negative impact on the supply-side of the market. In addition, tighter monetary policy to curb the pressure induced by oil price increases on headline inflation is likely to reduce liquidity from the housing market and hence, result in a decline in demand for housing. Further, in the wake of inflation, if housing is used as a hedge, the inflationary-effect of oil prices might actually end up increasing housing demand. Finally, following oil price hikes, investment opportunities in the oil (energy) sector, in the wake of its financialization, might lead to portfolio allocation away from housing, and thus affect its demand negatively. Clearly, oil shocks can impact both demand and supply-sides of the market via multiple channels, and in the process affect the aggregate real estate uncertainty resulting from the movements of several housing market variables via the sudden impact of oil price changes.

Against this backdrop, we aim to add to this line of research, by analysing for the first time the predictive role of disentangled oil (supply, global economic activity, oil-specific consumption demand and oil inventory demand) shocks as derived by Baumeister and Hamilton (2019), on monthly REU of the US over 1975:02 to 2017:12, which too is expected to be affected through the same channels the oil market impacts on overall macroeconomic uncertainty (MU) and financial uncertainty (FU). As pointed out above, REU has been shown to be an important leading driver of not only the housing market - which constitutes a significant share of many households' asset holding and net worth, ${ }^{1}$ but also output, hence, predicting real estate uncertainty remains an important policy question. This is more so since Gabauer and Gupta (2020) point out that REU actually spills over to also MU and FU as well, which in turn implies the prolonged effect of an uncertainty shock on the economy due to the interactions between various sectoral measures of uncertainty. Furthermore, if REU is predictable, it also implies that when identifying REU shock in structural macroeconometric model to analyse its impact on other economic variables via impulse response functions, econometricians must be cognizant of the fact that, REU cannot be treated as an exogenous variable.

From an econometric perspective, the four structural oil shocks are used to obtain impulse response functions for the REU by feeding them into the local projection method of Jordà (2005). The remainder of the paper is organized as follows: Section 2 discusses the data and outlines the econometric methodology, while Section 3 presents the results, with Section 4 concluding the paper.

1 According to the Financial Accounts data (downloadable from: https://www.federalreserve.gov/releases/z1/20190920/html/b101h.htm) of the US corresponding to the fourth quarter of 2018, residential real estate represents about $83.7 \%$ of total household non-financial assets, $28.3 \%$ of total household net worth and $24.6 \%$ of household total asset. 


\section{Data and Methodology}

Our data set covers the monthly period of 1975:02 to 2017:12, with the start and end date being driven respectively, by the availability of oil shocks of Baumeister and Hamilton (2019), and real estate uncertainty (REU) index developed by Nguyen Thanh et al. (2018), whose methodological framework for the construction of the REU measure follows that of Jurado et al. (2015). Specifically speaking, the macroeconomic uncertainty (MU) and financial uncertainty (FU) measures of Jurado et al. (2015) and Ludvigson et al. (forthcoming), is the average time-varying variance in the unpredictable component of 134 macroeconomic and 148 financial time-series respectively, i.e., it attempts to capture the average volatility in the shocks to the factors that summarize real and financial conditions. ${ }^{2}$ Given this, Nguyen Thanh et al. (2018) link uncertainty directly to the predictability of 40 housing market variables. ${ }^{3}$ The various uncertainty indices are available for three forecasting horizons of 1-, 3-, and 12-monthahead, which in turn enables us to analyze short, medium- and long-term impact of the structural oil shocks on REU1, REU3 and REU12, controlling for the effects of MU1 and FU1; MU3 and FU3, and; MU12 and FU12. As far as the four structural oil-shocks, i.e., supply, global economic activity, oil-specific consumption demand and oil inventory demand concerned, these are obtained from the structural vector autoregressive (SVAR) model of Baumeister and Hamilton (2019), who formulate a less restrictive framework, than what has been traditionally used in the literature following Kilian (2009), by incorporating uncertainty about the identifying assumptions of the SVAR. In other words, the obtained oil shocks can be considered to be relatively more accurately estimated, with each of them capturing distinct aspects regarding the demand and supply sides of the oil market. In other words, the shocks do not contain overlapping information.

We then use the local projection (LP) method of Jordà (2005) to estimate, using ordinary least squares (OLS), the impulse response functions (IRFs) of REU1, REU3 or REU12 for the various oil shocks, and controlling for the corresponding MUs and FUs, given the evidence of spillover across the measures of uncertainty as noted by Gabauer and Gupta (2020). The linear model for calculating IRFs is as follows:

$R E U j_{t+s}=\alpha_{s}+\beta_{s}$ Oil Shock $_{t}+\gamma_{s}(L) X_{t-1}+\epsilon_{t+s}$, for $s=0,1,2, \ldots h$,

where $R E U j_{t}$ represents the real estate uncertainty at time $t$ horizons $j=1,3$ and 12, Oil Shock captures an identified oil shock at time $t, X$ is a vector of control variables, $\gamma_{S}(L)$ is a polynomial in the lag operator, $s$ is the length of forecast horizons, $h$ is the maximum length of forecast horizons. ${ }^{4}$ Our vector of control variables $X$ contains MUs and FUs of the corresponding horizons, as well as lags of REU to control for any serial correlation in the variable. The values of the four structural oil-shocks, i.e., the oil supply shock (OSS), economic activity shock (EAS), oil-specific consumption demand shock (OCDS) and oil inventory demand shock (OIDS) are considered one at a time in the model, as part of the oil shock component of equation (1). $\beta_{s}$ measures responses of uncertainty at time $t+s$ to the one unit increase in the identified oil price shock at time $t$. The IRFs can be constructed as a sequence

\footnotetext{
${ }^{2}$ The MU and FU indices are available for download from the website of Professor Sydney C. Ludvigson: www.sydneyludvigson.com/data-and-appendixes.

3 The REU index is downloadable from the website of Professor Johannes Strobel: https://sites.google.com/site/johannespstrobel/.

${ }^{4}$ The maximum length of forecast horizons is set to 24 , which corresponds to 24-month forecast horizons. $\gamma_{S}(L)$ is a polynomial of order 12 , which corresponds to 12 -month lags for control variables.
} 
of $\beta_{s}$ estimated in a series of single regressions for each horizon $(s) .{ }^{5}$ Note that, the impulse responses can be computed without specification and estimation of the underlying multivariate dynamic system. The central idea consists in estimating local projections at each period of interest rather than extrapolating into increasingly distant horizons from a given model, as it is done with VAR. In other words, the analysis of the responses of REUs to the oil shocks does not require identification based on a certain scheme, say for example the Cholesky decomposition.

\section{Empirical Results}

In Figures 1(a), 1(b) and 1(c), we present the impact of the four structural oil shocks on REU1, REU2 and REU3. The figures track the responses calculated by local linear projections to the disaggregated oil shocks on the future path of the REUs for 1 to 24-month-ahead, along with the $68 \%$ confidence bands, which in turn is recommended to tackle possible inefficiency in the local linear projection approach, due to the fact that the model does not use an iterative procedure to produce impulses, as is the case in a VAR model (Carcel, 2018). Moreover, since uncertainty is latent, and need to be generated from data using econometric approaches, it is important that we deal with possible measurement errors by using narrower confidence bands, associated with $68 \%$. First starting with the signs of the IRFs, we find that REU1, REU3 and REU12 fall following positive aggregate supply and global economic activity shocks, while REUs increases in the wake of positive oil-specific consumption demand and oil inventory demand shocks. The sign of the effects is in line with intuition. A positive aggregate supply shock, which implies an increase in oil production and a decline in oil price enhances domestic economic uncertainty and reduces uncertainty associated with the real estate sector. At the same time, an expansion in global economic activity though drives oil prices higher, is a sign of a booming world economy, which in turn is also likely to reduce uncertainty. Note both the increase in aggregate supply and global economic activity are perceived as positive news, and hence is associated with reduced uncertainty. As far as the oil-specific consumption demand and inventory demand shocks are concerned, these two oil market innovations are associated with oil price increases and are capturing precautionary and speculative behaviour in the oil market, which results in enhanced real estate uncertainty, due to economic agents considering these shocks as negative news. In sum, we find that stronger impacts of the oil shocks are observed at longer forecast horizons, which in turn should not come as a surprise, since housing market, unlike the financial sector, is characterized by sluggish consumer and investor decisions.

\footnotetext{
${ }^{5}$ Let us suppose that we want to generate an IRF for a shock to $x_{t}$ on itself, i.e., we consider an univariate process. The first step is to choose the size of the shock $u$. At the time of the shock, $E\left[x_{t}\right]$, the point estimate for the shock at the time of impact (which has been set as period $t$ ) is then simply $x+u$, where $x$ is typically the mean. The next step is to choose, how many lags to include in the estimated autoregressive process. For the sake of simplicity of exposition, suppose we choose two lags, though in our case, we work with 12 lags. The next period of the IRF function is then obtained by regressing $x_{t}$ on two lags of itself, i.e., $x_{t}=\alpha+\beta_{1} x_{t-1}+\beta_{2} x_{t-2}+u_{t}$. The IRF estimate for the period after the shock is then: $E\left[x_{t+1}\right]=\alpha+\beta_{1}(\bar{x}+\bar{u})+\beta_{2} \bar{x}$, and the confidence interval will be computed using the standard errors of the regression coefficients. At this point, the local projections method deviates from the traditional approach used in the VAR (as it does not rely on the iteration of older and possibly misspecified expectations). It forms $E\left[x_{t}+2\right]$ and each subsequent period using a separate OLS regression. In order to obtain the IRF for $t+2$ one needs to regress $x_{t}$ on $x_{t-2}$ and $x_{t-3}$, i.e., i.e., $x_{t}=\alpha+\beta_{1} x_{t-2}+\beta_{2} x_{t-3}+u_{t}$, and again $E\left[x_{t+2}\right]=\alpha+\beta_{1}(\bar{x}+$ $\bar{u})+\beta_{2} \bar{x}$, and it is straightforward to compute the confidence interval. However, the coefficients now take different values, with each period getting its own regression. Further technical details about LP IRFs can be found in Jordà (2005).
} 
Figure 1. Impact of Disaggregated Oil Shocks on Real Estate Uncertainty (REU) at Horizons 1-, 3-, and 12-Month-Ahead:

Figure 1(a). Impact on REU at horizon 1 (REU1)
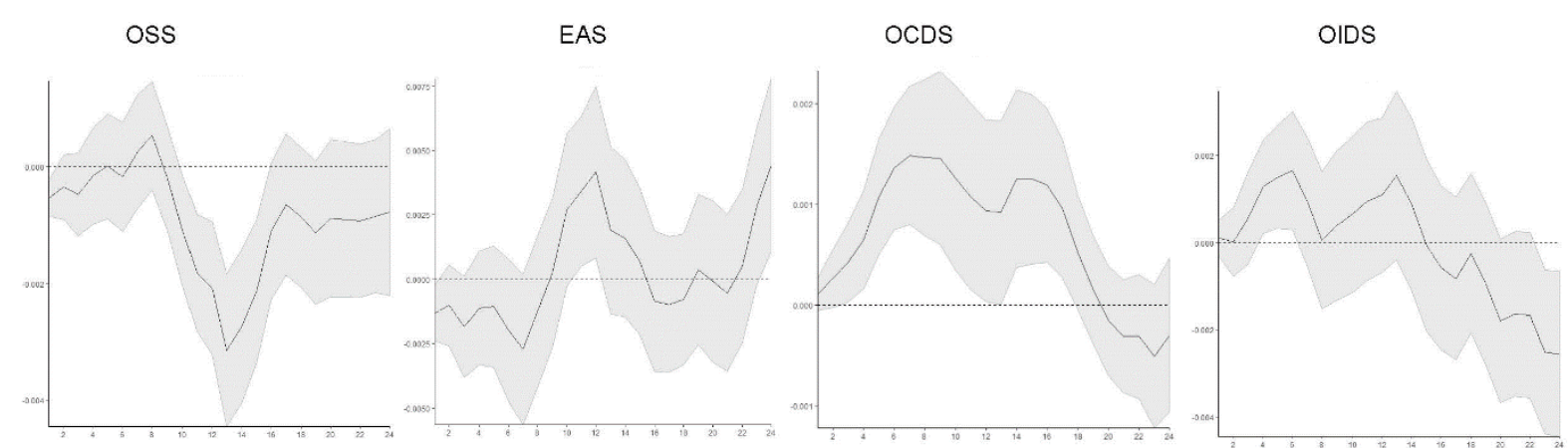

Figure 1(b). Impact on REU at horizon 3 (REU3)
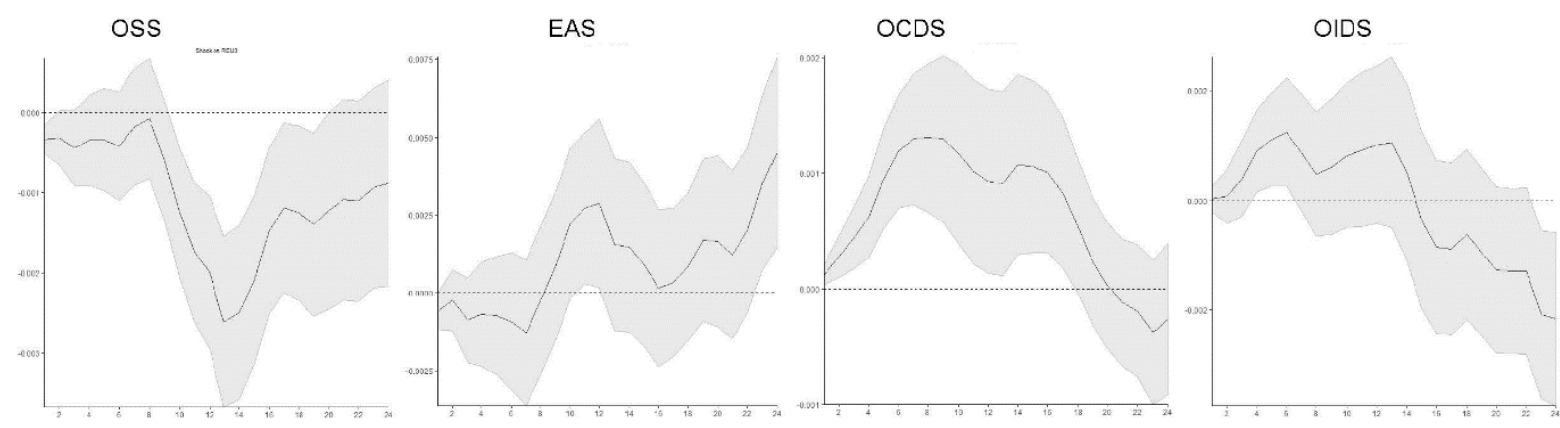
Figure $1(c)$. Impact on REU at horizon 12 (REU12)
OsS

EAS

OCDS

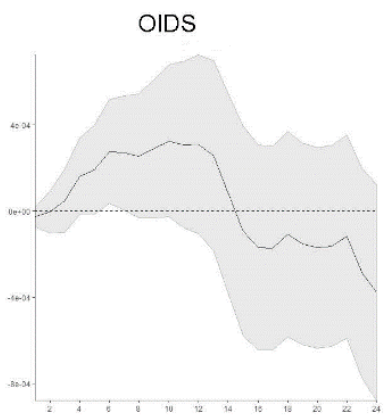

Note: The figures show impulse responses to a 1 unit increase in disaggregated oil shock. The shaded areas represent the $68 \%$ confidence bands; OSS: oil supply shock; EAS: economic activity shock; OCDS: oil-specific consumption demand shock; OIDS: oil inventory demand shock.

While the signs are economically meaningful, what is important is to check the statistical significance of the IRFs. The negative impact on REU1 and REU3 due to the aggregate supply shock is significant for the initial 3-months after the shock, and then after a year for 12 to 16 months and 12 to 20 months respectively. The most persistent significant impact of the supply shock is felt at by REU in the longer-run, i.e., REU12, whereby the impact is mostly significant till 20-month-ahead, probably suggesting that as high oil production feeds into low oil prices, it positively impacts constructions in the housing sector, and hence affects longer-run uncertainty more strongly, as building takes time. Unlike the aggregate supply shock, the impact on the REUs across all horizons under the global economic activity shock is not significant. The increase in REU1 and REU3 due to the oil inventory shock is significant after 
a delay between the 4- to 8-month-ahead forecasting horizon, but the effect limited to between 6-to 8-month-ahead for REU12. Strong evidence of statistical significance is observed under the oil-specific demand shock, with the impact lasting for over one and a half-year. In sum, precautionary demand for oil over uncertainty about future oil supply, i.e., the oil-specific demand shock, just like the findings in the existing literature analysing the impact of oil shock on macroeconomic and financial uncertainty (see for example Kang and Ratti (2013a, 2013b)), is the main driver of also real estate uncertainty. This is followed by the aggregate supply shock, particularly for long-run uncertainty, with some limited short-lived impact from the speculative inventory oil demand shocks. ${ }^{6,7}$

\section{Conclusion}

Uncertainty related to the real estate market has been shown to negatively impact the housing market and economic activity of the US. Given this, prediction of real estate uncertainty (REU) is invaluable to both investors and policymakers in gauging the future path of the housing sector and the overall macroeconomy. Building on the recent literature of predicting macroeconomic and financial market uncertainties based on movements of the oil price, we analyse the role played by disaggregated oil shocks in driving REU over the monthly period of 1975:02 to 2017:12. Using impulse response functions generated from the local projection method, we find that oil-specific consumption demand shock is statistically the strongest predictor of higher future REU, followed by significant negative impact from the aggregate supply shock, especially for long-run uncertainty, with the oil inventory demand shock producing short-lived positive impact on REUs. Interestingly, global economic activity shocks virtually play no role in affecting the future path of REUs. Understandably, policy authorities and economic agents monitoring uncertainty in the real estate sector need to carefully follow the behaviour of oil prices, especially when it results from the precautionary oil-specific consumption demand shock, and in addition from the oil supply shock, in particular for long-run REU. In addition, REU is predictable based on information of oil shocks, and hence, it can be considered endogenous, given that oil shocks are known to affect the overall macroeconomy and financial markets. This is an important finding from the perspective of how a real estate-related uncertainty shock is actually identified in structural macroeconometric models. Specifically speaking, since real estate uncertainty is actually a predictable variable, then it cannot be treated as exogenous for structural analysis, for example, while obtaining impulse response functions

\footnotetext{
${ }^{6}$ Based on the suggestion of an anonymous referee, we found that standard linear Granger causality test reveals strong influence of the OSS for REUs at all horizons, and EAS and OIDS significantly impacted REU12 and REU3 respectively. Complete details of these results are available upon request from the authors.

${ }^{7}$ As a robustness check, we analysed the impact of the four oil shocks on the conditional volatility of nominal housing returns, often measured as housing market uncertainty (see for example, Christidou and Fountas (2018)), derived using the exponential generalized autoregressive conditional heteroscedasticity (EGARCH) model of Nelson (1991) (since it produced the best fit among alternative symmetric and asymmetric GARCH models). Note the seasonally-adjusted housing price data is derived from Freddie Mac (with the data downloadable from: http://www.freddiemac.com/research/indices/house-price-index.page), and the model is estimated over the same sample period of 1975:02 to 2017:12 for the sake of comparability. This house price index provides a measure of typical price inflation for houses within the United States and is based on expanding database of loans purchased by either Freddie Mac or Fannie Mae. As observed from Figure A1 reported in the Appendix, the IRFs follow a general pattern as those reported for REUs, but are more volatile. Interestingly in this case, the global economic activity shock is found to produce statistically the most pronounced negative impact on housing market volatility, with delayed statistically significant intermittent negative effects also observed under the aggregate supply shock. The oil inventory demand shock is found to produce delayed positive short-lived impact on housing returns volatility. Complete estimation details of the underlying EGARCH model is available upon request from the authors.
} 
of economic variables, following a shock to uncertainty of the real estate sector. In other words, while accurate predictability of real estate uncertainty is important for policymakers, the same has important implication for structural modelling simultaneously.

As part of future research, it would be interesting to extend our analysis to an out-of-sample forecasting exercise, given that in-sample predictability of the REU does not guarantee out-ofsample forecasting gains emanating from oil shocks. Also, contingent on availability of data associated with real estate uncertainty, the analysis can be extended to oil-importing and oilexporting countries, with the possibility of comparing the latter group with the US.

\section{References}

Antonakakis, N., Gupta, R., and Muteba Mwamba, J.W. (2016). Dynamic Comovements between Housing and Oil Markets in the US over 1859 to 2013: A Note. Atlantic Economic Journal, 44(3), 377-386.

Baumeister, C., and Hamilton, J.D. (2019). Structural Interpretation of Vector Autoregressions with Incomplete Identification: Revisiting the Role of Oil Supply and Demand Shocks. American Economic Review, 109(5), 1873-1910.

Carcel, H., Gil-Alana, L.A., and Wanke, P. (2018). Application of local projections in the monetary policy in Brazil. Applied Economics Letters, 25(13), 941-944.

Chuliá, H., Gupta, R., Uribe, J.M., and Wohar, M.E. (2017). Impact of US uncertainties on emerging and mature markets: Evidence from a quantile-vector autoregressive approach. Journal of International Financial Markets, Institutions and Money, 48(C), 178-191.

Christidou, M., and Fountas, S. (2018). Uncertainty in the housing market: evidence from US states. Studies in Nonlinear Dynamics \& Econometrics, 22(2), 1-17.

Degiannakis, S., Filis, G., and Panagiotakopoulou, S. (2018). Oil price shocks and uncertainty: How stable is their relationship over time? Economic Modelling, 72(C), 42-53.

Gabauer, D., and Gupta, R. (2020). Spillovers across Macroeconomic, Financial and Real Estate Uncertainties: A Time-Varying Approach. Structural Change and Economic Dynamics. 52, 167-173.

Gupta, R., Lau, C-K-M., and Wohar, M.E. (2019). The impact of US uncertainty on the Euro area in good and bad times: Evidence from a quantile structural vector autoregressive model. Empirica, 46, 353-368.

Gupta, R., Ma, J., Risse, M., and Wohar, M.E. (2018). Common business cycles and volatilities in US states and MSAs: The role of economic uncertainty. Journal of Macroeconomics, 57, 317-337.

Gupta, R., Olasehinde-Williams, G., and Wohar, M.E. (2020). The Impact of US Uncertainty Shocks on a Panel of Advanced and Emerging Market Economies. The Journal of International Trade \& Economic Development. DOI: https://doi.org/10.1080/09638199.2020.1720785.

Hailemariam, A., Smyth, R., and Zhang, X. (2019). Oil prices and economic policy uncertainty: Evidence from a nonparametric panel data model. Energy Economics, 83, 40-51. (2005).

Jordà, Ò. (2005). Estimation and Inference of Impulse Responses by Local Projections. American Economic Review, 95(1), 161-182.

Jurado, K., Ludvigson, S.C., and Ng, S. (2015). Measuring Uncertainty. American Economic Review, 105(3), 1177-1216.

Kang, W., and Ratti, R.A. (2013a). Structural oil price shocks and policy uncertainty. Economic Modelling, 35, 314-319.

Kang, W., and Ratti, R.A. (2013b). Oil shocks, policy uncertainty and stock market return. Journal of International Financial Markets, Institutions and Money, 26, 305-318. 
Kilian, L. (2009). Not all oil price shocks are alike: disentangling demand and supply shocks in the crude oil market. American Economic Review, 99, 1053-1069.

Ludvigson, S.C., Ma, S., and Ng, S. (Forthcoming). Uncertainty and Business Cycles: Exogenous Impulse or Endogenous Response? American Economic Journal: Macroeconomics. Mumtaz. H.. Musso. A. (2019). The evolving impact of global. region-specific and countryspecific uncertainty. Journal of Business \& Economic Statistics. DOI: https://doi.org/10.1080/07350015.2019.1668798.

Nelson, D.B. (1991). Conditional heteroskedasticity in asset returns: a new approach. Econometrica, 59, 347-370.

Nguyen Thanh, B., Strobel, J., and Lee, G. (2018). A New Measure of Real Estate Uncertainty Shocks. Real Estate Economics. DOI: https://doi.org/10.1111/1540-6229.12270.

\section{APPENDIX}

Figure A1. Impact of Disaggregated Oil Shocks on EGARCH-Based Conditional Volatility of Nominal Housing Returns

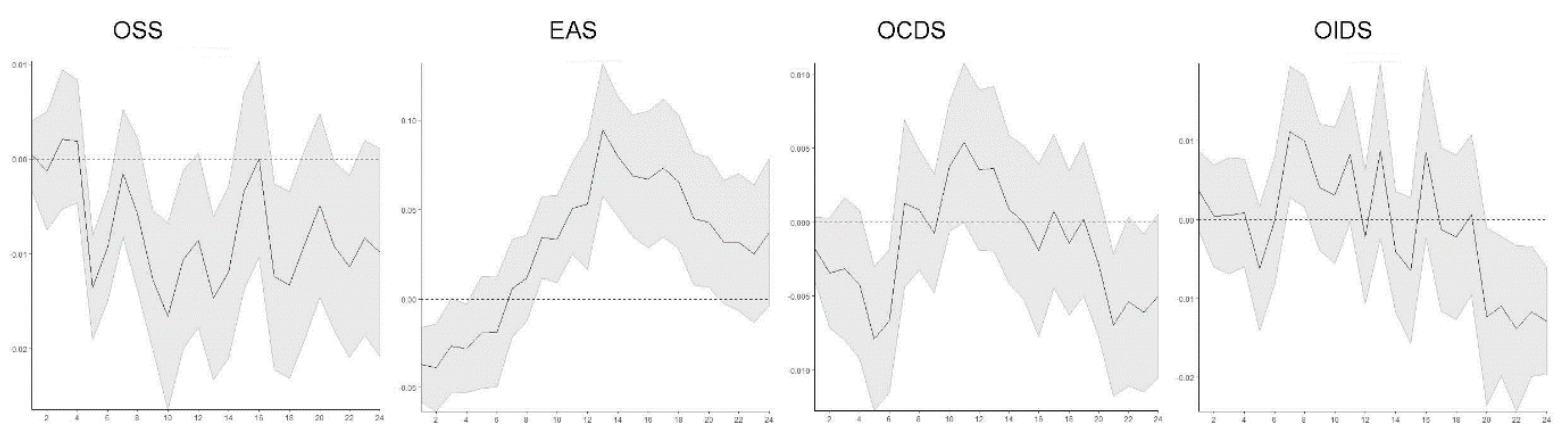

Note: See Notes to Figure 1. 